\title{
Design of Wearable Patch Antenna for Wireless Body Area Networks
}

\author{
Saqib Hussain, Saima Hafeez, Sajjad Ali Memon, Nasrullah Pirzada \\ Department of Telecommunication Engineering Mehran University of Engineering \& Technology Jamshoro, \\ Pakistan
}

\begin{abstract}
Wireless body area networks are being widely used due to the increase in the use of wireless networks and various electrical devices. A Wearable Patch antenna is used for enhancement of various applications for WBAN. In this paper, a low profile wearable microstrip patch antenna is designed and suggested for constant observation of human vital signs such as blood pressure, pulse rate and body temperature using wireless body area network (WBAN) technology. The operating frequency of the antenna is taken as $2.45 \mathrm{GHz}$ which lies in industrial, scientific and medical (ISM) frequency band. Polyester textile fabric with a relative permittivity of 1.44 and thickness of $2.85 \mathrm{~mm}$ is used as a substrate material. The proposed antenna is designed to achieve better return loss, VSWR, gain and low value of specific absorption rate (SAR) as compare to other existing wearable antenna. The achieved antenna return loss at $2.45 \mathrm{GHz}$ is about $\mathbf{- 1 0 . 5 2} \mathrm{dB}$ and gain of $7.81 \mathrm{~dB}$. The VSWR value achieved at $2.45 \mathrm{GHz}$ is 1.84 , which is good in terms of good impedance matching. Other antenna field parameters like 2D and 3D gain, radiation pattern, and SAR value have been calculated. High-Frequency Structure Simulator (HFSS) is used to design and simulate the proposed antenna.
\end{abstract}

Keywords-High-Frequency structure simulator (HFSS); return loss; voltage standing wave ratio (VSWR); gain; specific absorption rate $(S A R)$

\section{INTRODUCTION}

Wireless Body Area Networks are being particularly used for the various real-time health monitoring applications. These networks include the use of wearable antennas for transmitting and receiving of the data for healthcare related systems. An antenna that is integrated into the clothing of the wearer is called a wearable antenna. A wearable antenna can be used in a variety of applications such as GPS navigation, military, monitoring of athletes fitness, telemedicine, satellite communication, digital watches, and RFID [1]-[3]. Advancements in the field of wearable electronics have progressed rapidly in recent times and as a result, intensive research activities are being held over body conformal antennas. These days, some vital signs of the human body such as heart rate, blood glucose, blood pressure, and electrocardiogram (ECG) need to be monitored regularly due to their severe implications on the human health. Therefore, multiple sensors can be placed on the human body to monitor those vital signs of the human body [4]-[6]. The body-worn sensors store information regarding various physiological parameters and transmit them to the wearable devices, which further transmit them to the nearest receiving node. On-body communication term is used when a wearable antenna communicates with a wearable medical device [7]. Whereas, off-body communication is said to be a communication between the on-body bio-medical transceiver device to external wireless transceiver device [8].

For the development of wearable antennas, $2.45 \mathrm{GHz}$ of industrial, scientific and medical (ISM) frequency band is employed due to its global availability. The wearable antenna must be hidden and low profile for the convenience of the user. This entails a thinkable amalgamation of the antenna elements within daily life outfit. Microstrip patch antenna can be an ideal choice for the wearable antenna applications [9].

There are various benefits of microstrip patch antenna as it is lightweight, compact, flexible and able to resist mechanical strain without affecting antenna performance significantly [10]. A wearable antenna can be used to communicate between sensors and the human body. Due to its small and compact size, a wearable antenna is utilized in different applications such as for military, medical, healthcare, emergency services, and navigation. In a military application, it is used to establish communication links between different soldiers including sending images and videos, location tracking and army protection. Furthermore, medical applications are used to check and monitor health parameters of a patient and can communicate with each other or with the outside world [11].

Various types of wearable sensors are mounted on or implanted into the human body in order to access human vital signs information such as body temperature, blood pressure, and heartbeat. The medical information is then sent through sensors to the receiver at low frequency. After the reception of medical information, all the data is collected from the sensors mounted on the human body and then, sent to an external device. The doctor in the hospital or any remote location can look after the situation of the patient and suggest medicines immediately to improve the quality of healthcare [12]-[13].

The formation of this paper is as follows. Section II discusses the literature review and other works related to wearable microstrip patch antenna. The antenna designing steps are explained in Section III, IV, V, VI, and VII, respectively. Section VIII discusses the results and compares them with the other works. Finally, some conclusions are drawn in Section IX and future work suggestions are presented at the end.

\section{LITERATURE REVIEW}

Microstrip patch antenna has many advantages as it is lighter in weight, low cost, low profile than the conventional 
microwave antenna. The planar structure of the antenna provides ease of fabrication [14]. Presently, it has been observed that the microstrip patch antenna become an ideal choice for the wearable healthcare applications. However, human body tissues can affect the performance and efficiency of the antenna, therefore, the selection of the material used to design such kind of antenna plays a significant role [15]. Also, the antenna performance and the radiation pattern are greatly influenced by the absorbed energy. The Specific Absorption Rate (SAR) is used to measure the amount of power absorbed by human body tissues. According to Federal Communication Commission (FCC), the SAR value should be below $1.6 \mathrm{~W} / \mathrm{Kg}$ averaged over $1 \mathrm{gm}$ of tissue and in European Standard, its value should be $2 \mathrm{~W} / \mathrm{Kg}$ averaged over $10 \mathrm{gm}$ of tissue [16][17].

An e-textile patch antenna was designed by the authors [18] for the frequency of $5.8 \mathrm{GHz}$ using jeans as a substrate material. The measured return loss $\left(\mathrm{S}_{11}\right)$, gain and $\mathrm{SAR}$ values are $-21 \mathrm{~dB}, 3.05 \mathrm{~dB}$, and $0.0111 \mathrm{~W} / \mathrm{Kg}$ respectively. In [19], the authors have presented the flexible antenna design for the purpose of telemedicine applications. The authors used 2 substrate materials to design wearable antenna i.e. cotton and jeans. The jeans material has shown good results in terms of gain over cotton which is $5 \mathrm{~dB}$ compared to a gain of $3 \mathrm{~dB}$ for cotton. In [20], the authors have proposed a wearable patch antenna design using FR-4 as a substrate material covered by the jeans fabric as the outer layer. The measured antenna parameters such as return loss $\left(\mathrm{S}_{11}\right)$ of $-15.28 \mathrm{~dB}$ and a gain of $5.209 \mathrm{dBi}$ at a frequency of $2.4 \mathrm{GHz}$. Similarly, in [21], the authors have designed and fabricated the wearable antenna on a flexible substrate material known as denim gens. This antenna can be used to operate in various frequency bands such as $\mathrm{L}, \mathrm{S}$, $\mathrm{C}$, and $\mathrm{X}$ with both horizontal and vertical polarization.

\section{METHODOLOGY}

The proposed antenna is designed and simulated using the High-Frequency Structure Simulator (HFSS). The suggested antenna is a microstrip patch antenna, therefore its design in HFSS needs some geometrical and simulation parameters. The geometrical parameters of the proposed antenna are calculated using microstrip equations discussed in Section IV. However, the major simulation parameter of an antenna is a frequency that can be defined according to the application of the proposed antenna [22]-[23]. After the computation of geometrical parameters, the design of the suggested antenna can be modeled in the HFSS. The general methodology to model a patch antenna in HFSS is explained in the flow chart given below in Fig. 1.

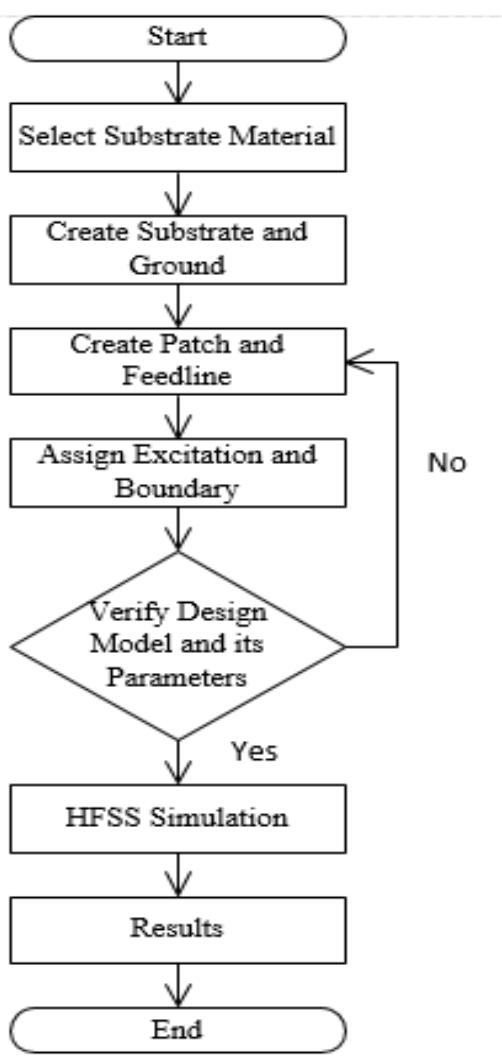

Fig. 1. The antenna simulation flowchart in HFSS

\section{Design of Proposed Wearable Patch Antenna}

Microstrip line inset feeding technique is utilized to design the proposed wearable patch antenna. The inset fed technique is used because it provides the planar structure to the antenna. The operating frequency of the antenna is taken as $2.45 \mathrm{GHz}$ because it is unlicensed and can be used for a variety of applications. The patch antenna is fed by $50 \Omega$ input impedance. This antenna is implemented on the polyester substrate material that has a low dielectric constant, which results in a reduction in the surface wave losses. The relative permittivity $\in_{r}$ of substrate material is 1.44 , the thickness $h$ is $2.85 \mathrm{~mm}$ and the loss tangent $\tan \sigma$ is 0.01 . The substrate dimension is $90 \times 90 \mathrm{~mm}^{2}$. As microstrip inset fed technique is utilized to design the proposed antenna. Antenna geometrical parameters such as patch width $W_{p}$ and patch length $L_{p}$ have been computed using the following formulas mentioned below. [22]. 


$$
\begin{gathered}
W_{p}=\frac{c}{2 f_{o}}\left(\frac{2}{\epsilon_{r}+1}\right)^{\frac{1}{2}} \\
L_{p}=\frac{1}{2 f_{o} \sqrt{\epsilon_{\text {reff }} \mu_{o} \epsilon_{o}}}-2 \Delta L
\end{gathered}
$$

Where $c, f_{o}, \in_{r}, \in_{r e f f}, \mu_{o}$ and $\Delta L$ is the speed of light, operating frequency, dielectric constant, effective dielectric constant, the permeability of the free space and extension length, respectively. Whereas, the extension length $\Delta L$ and the effective dielectric constant $\epsilon_{\text {reff }}$ is computed by the subsequent equations [23].

$$
\begin{gathered}
\Delta L=0.412 h\left[\left(\frac{\epsilon_{\text {reff }}+0.3}{\epsilon_{\text {reff }}-0.258}\right)\left(\frac{\frac{W_{p}}{h}+0.264}{\frac{W_{p}}{h}+0.813}\right)\right] \\
\in_{\text {reff }}=\frac{\epsilon_{r}+1}{2}+\frac{\epsilon_{r}-1}{2}\left(1+\frac{12 h}{W_{p}}\right)^{\frac{-1}{2}}
\end{gathered}
$$

After obtaining all the values of antenna geometrical parameters, the suggested wearable patch antenna is designed in antenna simulation software named as HFSS and polyester fabric is utilized as a substrate material whose loss tangent value is 1.44 . The input impedance of the proposed antenna is characterized by $50 \Omega$.

\section{SUBSTRATE MATERIAL}

The substrate material used to design wearable antenna is polyester. The main advantage of selecting the polyester material as a substrate is its flexibility. Furthermore, it is used in daily life fabric and readily available in the market. The material characteristics listed in TABLE I are as follows:

TABLE I. Substrate Material Design Values

\begin{tabular}{|c|c|c|}
\hline RS PARAMETE & $\begin{array}{c}\text { SYM } \\
\text { BOL }\end{array}$ & \multicolumn{2}{|c|}{ VA } \\
\hline $\begin{array}{c}\text { Dielectric } \\
\text { constant }\end{array}$ & $\varepsilon_{\mathrm{r}}$ & \multicolumn{2}{|c|}{1.4} \\
\hline Loss tangent & $\tan \sigma$ & \multicolumn{1}{c|}{0.0} \\
\hline Thickness & $\mathrm{h}$ & $\begin{array}{c}2.8 \\
5 \mathrm{~mm}\end{array}$ \\
\hline
\end{tabular}

\section{DimENSIONS OF PATCH ANTENNA}

The dimensions of patch antenna play a pivotal role to make an effective antenna design in terms of efficient results. TABLE II illustrates the calculated parameters of the suggested patch antenna model.
TABLE II. PATCH ANTENNA DESIGN VALUES

\begin{tabular}{|l|l|l|}
\hline PARAMETERS & SYMBOL & VALUE \\
\hline Operating Frequency & $f_{o}$ & $2.45 \mathrm{GHz}$ \\
\hline Patch Dimension Along x & $W_{p}$ & $55.43 \mathrm{~mm}$ \\
\hline Patch Dimension Along y & $L_{p}$ & $47.9 \mathrm{~mm}$ \\
\hline Substrate Thickness & $h$ & $2.85 \mathrm{~mm}$ \\
\hline Substrate Dimension Along x & $W_{s}$ & $90 \mathrm{~mm}$ \\
\hline Substrate Dimension Along y & $L_{s}$ & $90 \mathrm{~mm}$ \\
\hline Inset Distance & $Y_{o}$ & $10 \mathrm{~mm}$ \\
\hline Inset Gap & $G$ & $2 \mathrm{~mm}$ \\
\hline Feed Width & $W_{f}$ & $3.3 \mathrm{~mm}$ \\
\hline Feed Length & $L_{f}$ & $24 \mathrm{~mm}$ \\
\hline Di electric constant of substrate & $\epsilon_{r}$ & 1.44 \\
\hline Input Impedance & $Z_{o}$ & $50 \Omega$ \\
\hline
\end{tabular}

VII. DESIGN OF Human PHANTOM MODEL

A 3-layer human phantom model is created in HFSS for the calculation of specific absorption rate (SAR). The 3-layer human phantom model consists of 3 layers of human body tissues i.e. muscle, fat, and skin. The width of muscle, fat, and skin are $23 \mathrm{~mm}, 8 \mathrm{~mm}$ and $2 \mathrm{~mm}$, respectively. TABLE III. illustrates the different values of human body tissues that are taken to create the human phantom model. In order to study SAR impact in the vicinity of the human body, the proposed wearable antenna is mounted on a $110 \times 110 \mathrm{~mm}^{2}$ bodyphantom model. Fig. 2 illustrates the proposed antenna on human body phantom model.

TABLE III. PROPERTIES OF HUMAN BODY TISSUES

\begin{tabular}{|l|l|l|l|l|}
\hline Tissue & $\begin{array}{l}\text { Permittivity } \\
\left(\boldsymbol{\varepsilon}_{\mathbf{r}}\right)\end{array}$ & $\begin{array}{l}\text { Conductivity } \\
(\mathbf{S} / \mathbf{m})\end{array}$ & $\begin{array}{l}\text { Loss } \\
\text { Tangent }(\tan \\
\boldsymbol{\sigma})\end{array}$ & $\begin{array}{l}\text { Density } \\
\left(\mathbf{K g} / \mathbf{m}^{\mathbf{3}}\right)\end{array}$ \\
\hline Skin & 31.29 & 5.0138 & 0.2835 & 1100 \\
\hline Fat & 5.28 & 0.1 & 0.19382 & 1100 \\
\hline Muscle & 52.79 & 1.705 & 0.24191 & 1060 \\
\hline
\end{tabular}

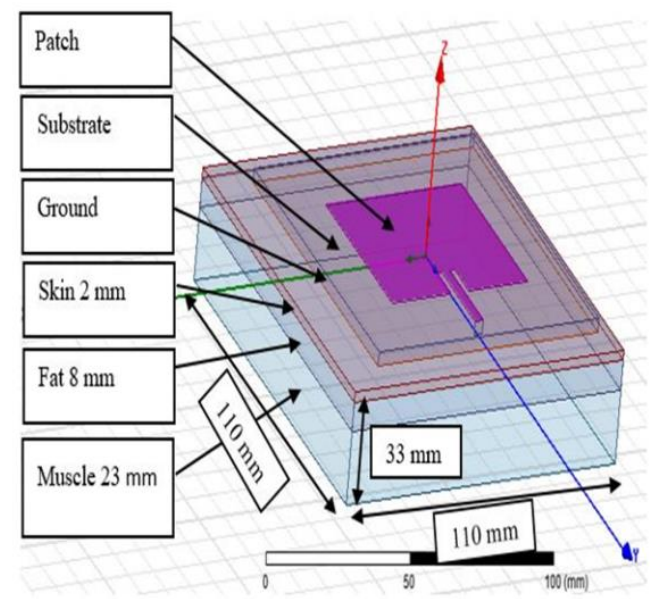

Fig. 2. Proposed Wearable Patch Antenna on Human Phantom Model 


\section{RESULTS AND DISCUSSION}

The proposed wearable patch antenna is simulated in HFSS antenna simulation tool using simulation parameters tabulated in TABLE II. The antenna is characterized by $50 \Omega$ input impedance. The scattering parameters $\left(S_{11}\right)$ return loss of the simulated antenna is illustrated in Fig. 3. The minimum return loss curve value achieved at $2.45 \mathrm{GHz}$ is $-10.52 \mathrm{~dB}$ i.e. marked by $\mathrm{m}_{2}$ and the achieved value is acceptable. Fig. 4 illustrates the 3D gain of the simulated antenna. At $2.45 \mathrm{GHz}$ the peak gain of $7.81 \mathrm{~dB}$ has been obtained in the z-axis i.e. perpendicular to the antenna. Fig. 5 illustrates the 2Dimensional gain of the antenna observed at $2.45 \mathrm{GHz}$. It can be seen that a peak gain of $7.81 \mathrm{~dB}$ i.e. marked by $\mathrm{m}_{1}$ is achieved at $0^{\circ}$. This radiated power is analyzed in the far-field region of the antenna. The directivity of the proposed wearable patch antenna is illustrated in Fig. 6. The values obtained from the simulation are suitable for the health monitoring applications. As can be seen from Fig. 6 that the directivity is exactly perpendicular to the axis, which implies that the power is focused in only one lobe. Fig. 7 illustrates the radiation pattern of the antenna. The theta values are taken from $0^{\circ}$ to $180^{\circ}$. It can be seen the major lobe of the antenna is radiating a majority of its power in the front direction, which concludes it has the high front to back ratio. In addition, it can be seen that the antenna has minimal minor lobes, which are very good for wearable applications.

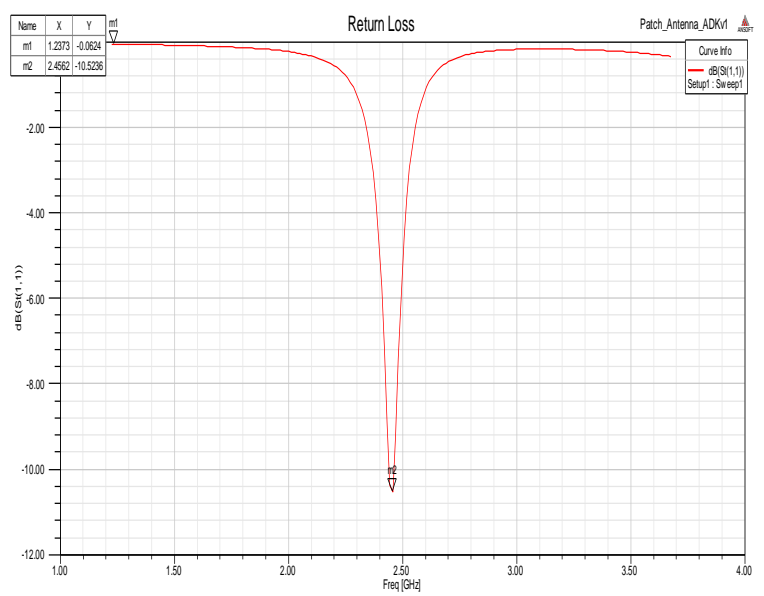

Fig. 3. Simulated Return Loss at $2.45 \mathrm{GHz}$
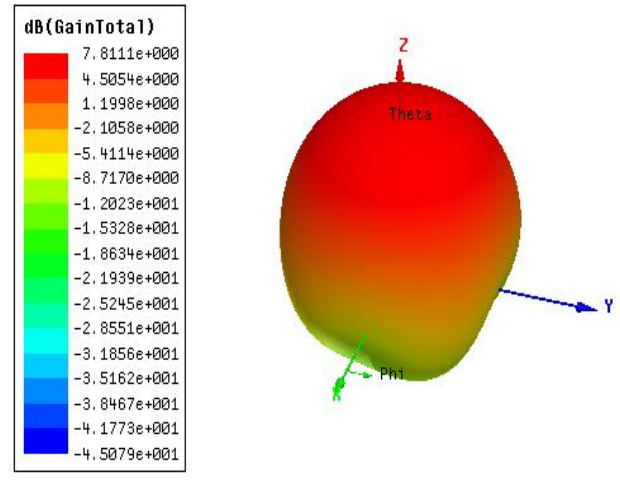

Fig. 4. Simulated 3D Gain at $2.45 \mathrm{GHz}$

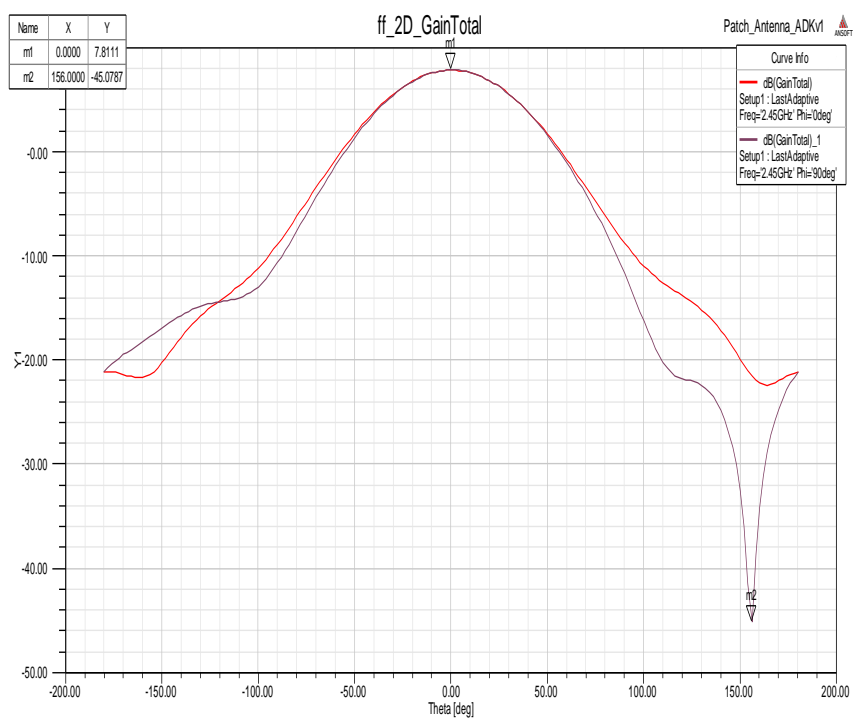

Fig. 5. Simulated 2D Gain at $2.45 \mathrm{GHz}$

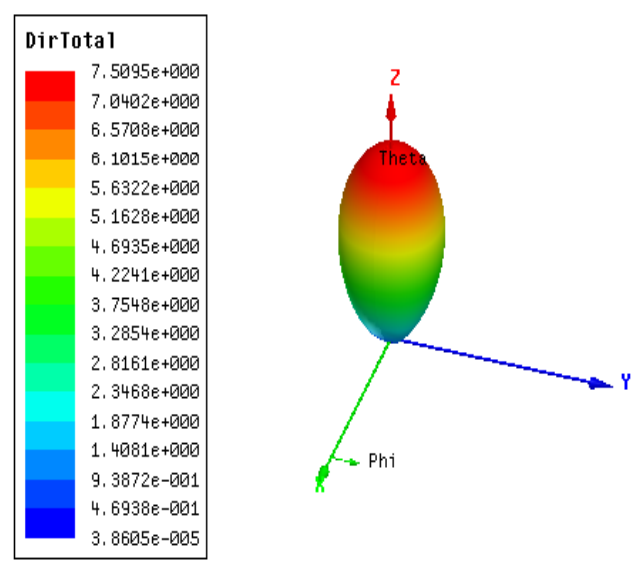

Fig. 6. Directivity of the Proposed Antenna

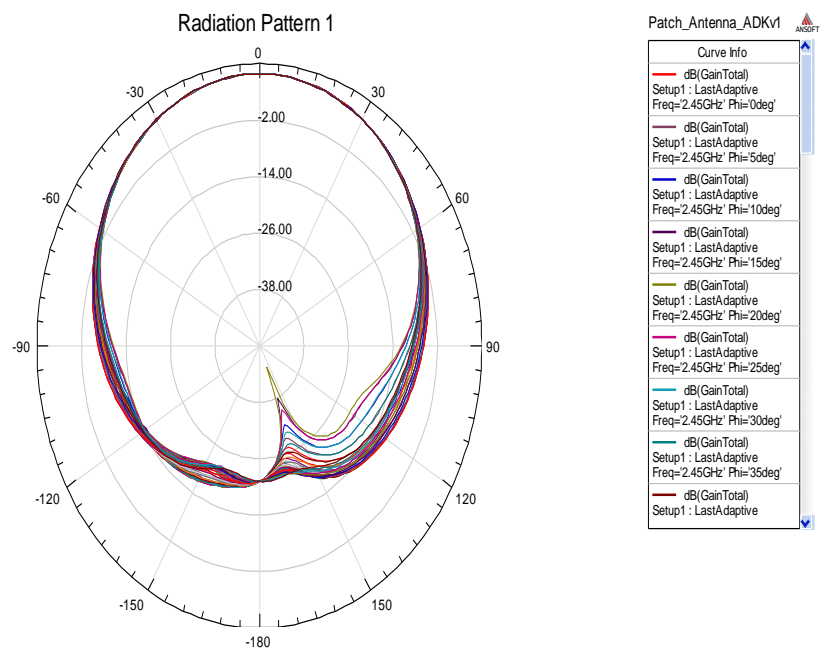

Fig. 7. Radiation Pattern of the Simulated Antenna 
Fig. 8 illustrates the Voltage Standing Wave Ratio (VSWR) is an indication of the quality of the impedance match. In the proposed antenna, the VSWR value achieved at $2.45 \mathrm{GHz}$ is 1.84 i.e. marked by $\mathrm{m}_{2}$. Fig. 9 shows the measured value of SAR on the phantom model at $2.45 \mathrm{GHz}$. The achieved SAR value at $2.45 \mathrm{GHz}$ is $0.0640 \mathrm{~W} / \mathrm{Kg}$ averaged over $1 \mathrm{gm}$ of tissue, which is under the limit of $1.6 \mathrm{~W} / \mathrm{Kg}$ averaged over 1 gm of tissue.

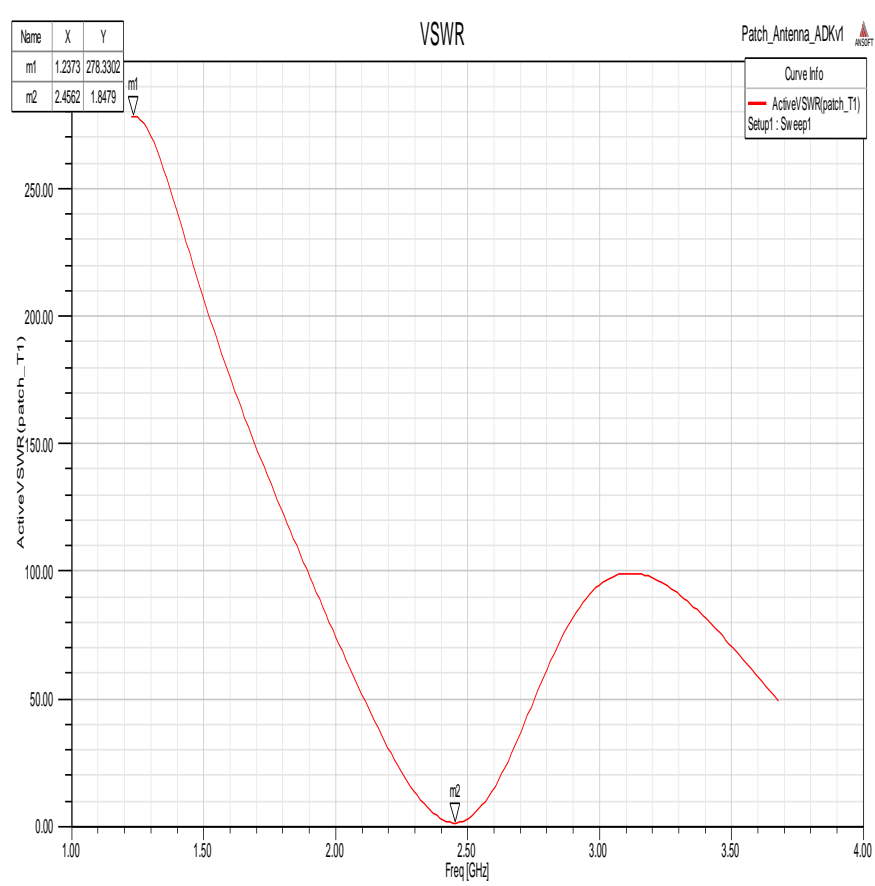

Fig. 8. VSWR of the Simulated Antenna

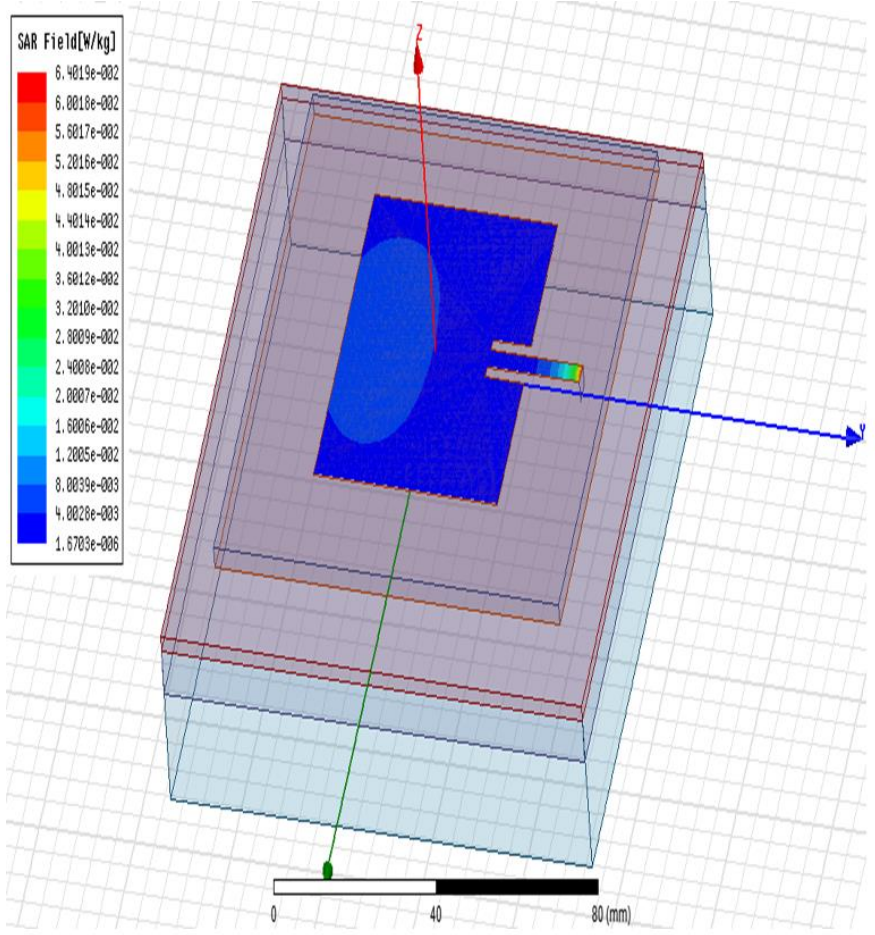

Fig. 9. SAR value of the Simulated Antenna at $2.45 \mathrm{GHz}$
TABLE IV. COMPARISON WITH OTHER RELATED WORKS

\begin{tabular}{|l|l|l|l|l|l|l|}
\hline Papers & $\begin{array}{l}\text { Operating } \\
\text { Frequency } \\
(\mathbf{G H z})\end{array}$ & $\begin{array}{l}\text { Size } \\
(\mathbf{m m})\end{array}$ & $\begin{array}{l}\text { Return } \\
\text { Loss } \\
(\mathbf{d B})\end{array}$ & $\begin{array}{l}\text { Gain } \\
(\mathbf{d B})\end{array}$ & VSWR & $\begin{array}{l}\text { SAR } \\
(\mathbf{W} / \mathrm{Kg})\end{array}$ \\
\hline $\begin{array}{l}\text { Our } \\
\text { Paper }\end{array}$ & 2.45 & $90 \times 90$ & -10.52 & 7.81 & 1.8 & 0.0640 \\
\hline$[18]$ & 5.8 & $40 \times 40$ & -21.52 & 3.05 & 1.1 & 0.0111 \\
\hline$[19]$ & 2.40 & $\begin{array}{l}90 \times \\
100\end{array}$ & -22.13 & 5.00 & 1.1 & - \\
\hline$[20]$ & 2.40 & $30 \times 37$ & -15.28 & $\begin{array}{l}5.20 \\
9 \mathrm{dBi}\end{array}$ & 1.4 & - \\
\hline$[21]$ & $1-10$ & $\begin{array}{l}120 \times \\
120\end{array}$ & -9.54 & 6.49 & 2 & - \\
\hline
\end{tabular}

TABLE IV shows the comparison of results of a wearable patch antenna with other related works. As can be seen from the table, the proposed antenna has an acceptable return loss, VSWR value and a high gain value compared to [18]-[21]. Specifically, the dimensions of the proposed antenna are slightly smaller than that of the [19] at the same operating frequency. Whereas, the return loss of the suggested antenna is better than that of the [21]. The antenna gain of the proposed antenna can be the certain factor value that is higher than all the other works mentioned in TABLE IV. Precisely, the gain of the suggested antenna is $4.76 \mathrm{~dB}, 2.81 \mathrm{~dB}, 2.5 \mathrm{~dB}$ and $1.32 \mathrm{~dB}$ higher than those of [18], [19], [20] and [21], respectively. Moreover, the specific absorption rate (SAR) value is quite low as compared to the FCC standard which is $1.6 \mathrm{~W} / \mathrm{Kg}$.

\section{CONCLUSION}

This paper proposes a wearable antenna that can be used for various applications such as monitoring of patients, navigation, and military applications. The rectangular patch antenna based on the inset fed patch technique has been designed on the textile material known as polyester. The substrate thickness is taken as $2.85 \mathrm{~mm}$. The relative permittivity and loss tangent values are 1.44 and 0.01 respectively. The Inset fed technique is used because it provides planar structure and can be easily fed by $50 \Omega$ impedance. The overall antenna dimensions are $90 \times 90 \mathrm{~mm}^{2}$.

The measured return loss achieved at $2.45 \mathrm{GHz}$ is -10.52 $\mathrm{dB}$ and a gain of $7.81 \mathrm{~dB}$ is obtained to ensure the efficient health monitoring. SAR is a very important parameter for wearable applications also SAR limit should have met the current standard set by IEEE which is $1.6 \mathrm{~W} / \mathrm{Kg}$ averaged over $1 \mathrm{gm}$ of tissue. The measured SAR value on the 3-layer human phantom model at $2.45 \mathrm{GHz}$ is $0.0640 \mathrm{~W} / \mathrm{Kg}$ averaged over 1 $\mathrm{gm}$. of tissue. The radiation pattern of the simulated antenna was perpendicular to the axis of the wearer, which means that this antenna is feasible for wearable applications and cannot harm the human body tissues due to its high front to back ratio. Also, the wearable antenna is the best way to be applied for wireless body area network communication and it has vast applications to provide real-time health monitoring.

\section{FUTURE WORK}

The future work can be done by improving the patch antenna bandwidth and efficiency. This can be done by increasing the height of the substrate material but it also increases the antenna dimensions. Also, the selection of textile 
material plays a significant role to enhance the antenna efficiency in terms of gain and bandwidth. Moreover, the performance of an antenna quickly deteriorates under wet conditions in order to avoid this, waterproof materials can be used for future wearable communication designs.

\section{REFERENCES}

[1] A. Khan, S. Bashir, and F. Ullah, "Electromagnetic Bandgap Wearable Dipole antenna with low Specific Absorption Rate," in 2018 International Conference on Computing, Mathematics and Engineering Technologies (iCoMET), 2018, pp. 1-4.

[2] H. R. Khaleel, H. M. Al-Rizzo, D. G. Rucker, and T. A. Elwi, "Wearable Yagi microstrip antenna for telemedicine applications," 2010 IEEE Radio Wirel. Symp. RWW 2010 - Pap. Dig., pp. 280-283, 2010.

[3] A. Y. I. Ashyap et al., "Inverted E-Shaped Wearable Textile Antenna for Medical Applications," IEEE Access, vol. 6, pp. 35214-35222, 2018.

[4] S. Bhattachaijee, S. Teja, S. R. B. Chaudhuri, and M. Mitra, "Wearable triangular patch antenna for ON/OFF body communication," 2017 IEEE Applied Electromagnetics Conference (AEMC), Aurangabad, 2017, pp. 1-2.

[5] S. Dumanli, "Challenges of wearable antenna design," 2016 46th European Microwave Conference (EuMC), London, 2016, pp. 13501352.

[6] R. Pei, J. Wang, M. Leach, Z. Wang, S. Lee and E. G. Lim, "Wearable antenna design for bio information," 2016 IEEE Conference on Computational Intelligence in Bioinformatics and Computational Biology (CIBCB), Chiang Mai, 2016, pp. 1-4.

[7] N. H. M. Rais, P. J. Soh, F. Malek, S. Ahmad, N. B. M. Hashim, and P. S. Hall, "A review of the wearable antenna," 2009 Loughborough Antennas \& Propagation Conference, Loughborough, 2009, pp. 225-228.

[8] K. Sajith, J. Gandhimohan, and T. Shanmuganantham, "A novel SRR loaded asymmetrical CPW fed ISM band wearable antenna for health monitoring applications," 2017 IEEE Applied Electromagnetics Conference (AEMC), Aurangabad, 2017, pp. 1-2.

[9] S. Sankaralingam and B. Gupta, "Development of Textile Antennas for Body Wearable Applications and Investigations on Their Performance Under Bent Conditions," Prog. Electromagn. Res. B, vol. 22, no. November, pp. 53-71, 2010.

[10] A. Sabban, "New Wideband Printed Antennas for Medical Applications," in IEEE Transactions on Antennas and Propagation, vol. 61, no. 1, pp. 84-91, Jan. 2013.

[11] Salleh, Binti and Suriani Mohd Sam. "A Review of Antenna for On Body Wearable Communication and Its Application.", Advanced Informatics
School, Universiti Teknologi Malaysia, Jalan Sultan Yahya Petra, Malaysia, (2016)

[12] K. Ito and Chia-Hsien Lin, "Dual-mode wearable antenna for medical applications," 2013 International Workshop on Antenna Technology (iWAT), Karlsruhe, 2013, pp. 372-375.

[13] X. Lin, S. Member, B. Seet, S. Member, and F. Joseph, "Flexible Fractal Electromagnetic Bandgap for Millimeter-Wave Wearable Antennas," IEEE Antennas Wirel. Propag. Lett., vol. 17, no. 7, pp. 1281-1285, 2018.

[14] I. Singh and V. S. Tripathi, "Microstrip Patch Antenna and its Applications : a Survey," International Journal of Computer Applications, vol. 2, no. 5, pp. 1595-1599, 2011.

[15] T. Patel and M. Sahoo, "Design Issues of Wearable Antennas," International Journal of Science and Research (IJSR), vol. 5, no. 5, pp. 2015-2017, 2016.

[16] A. J. Agaliya, T. M. Neebha, and M. Nesasudha, "Efficient wearable antenna design by patch area extension for body area network applications," 2016 International Conference on Communication and Signal Processing (ICCSP), Melmaruvathur, 2016, pp. 2130-2134.

[17] I. Gil and R. Fernandez-Garcia, "SAR impact evaluation on jeans wearable antennas," 2017 11th Eur. Conf. Antennas Propagation, EUCAP 2017, pp. 2187-2190, 2017.

[18] M. I. Ahmed, M. F. Ahmed, and A. A. Shaalan, "Novel Electrotextile Patch Antenna on Jeans Substrate for Wearable Applications," Progress in Electromagnetics Research C. 2018, Vol. 83, p255-265. 11p.

[19] G. Christina, A. Rajeswari, M. Lavanya, J. Keerthana, K. Ilamathi, and V. Manoranjitha, "Design and development of wearable antennas for telemedicine applications," 2016 International Conference on Communication and Signal Processing (ICCSP), Melmaruvathur, 2016, pp. 2033-2037.

[20] Zaini, SR Mohd, and KN Abdul Rani. "Wearable Inset-Fed FR4 Microstrip Patch Antenna Design." IOP Conference Series: Materials Science and Engineering. Vol. 318. No. 1. IOP Publishing, 2018.

[21] S. K. Jain, N. Baviskar, N. Golait, and S. Jain, "Design of Wearable Antenna for Various Applications," Antenna Test \& Measurement Society (ATMS India-18), pp. 2-6, 2018.

[22] Faisal Ahmed Dahri, Riaz A. Soomro, Sajjad Ali Memon, Zeeshan Memon, and Majid Hussain Memon, "An Optimized Inset Feed Circular Cross Strip Antenna Design for C-Band Satellite Links" International Journal of Advanced Computer Science and Applications (IJACSA), 9(5), 2018.

[23] Asif Ali, Nasrullah Pirzada, Muhammad Moazzam Jawaid, and Sajjad Ali Memon, "Design and Simulation of a Rectangular E-Shaped Microstrip Patch Antenna for RFID based Intelligent Transportation" International Journal of Advanced Computer Science and Applications (IJACSA), 9(4), 2018. 